\title{
Consolidation process model for film stacking glass/PPS laminates
}

\section{W. J. B. Grouve* and R. Akkerman}

A model is proposed to optimise the processing parameters for the consolidation of glass/ polyphenylene sulphide (PPS) laminates using a film stacking procedure. In a split approach, the heating and consolidation phase are treated separately. The heating phase is modelled using the one-dimensional heat conduction equation with variable thermal diffusivities. The model shows good agreement with experimental results. The consolidation phase is modelled using Darcy's law to predict the bundle impregnation time. The model predicts an impregnation time in the order of seconds, which is significantly shorter than the typical consolidation time of approximately 15 min used in practice. The impregnation model is validated in a comprehensive experimental programme, which included optical microscopy and mechanical testing. The experiments show that the consolidation time can indeed be shortened significantly for the glass/PPS system under consideration.

Keywords: Thermoplastic composites, Film stacking, Heat transfer, Consolidation, Process modelling

\section{Introduction}

The application of thermoplastic polymers as a matrix material in fibre reinforced composites has grown steadily over the last decades. ${ }^{1}$ Thermoplastic composites offer clear advantages over their thermoset counterparts in terms of improved fracture toughness, potential for recycling ${ }^{2}$ and, most notably, the possibility to reshape the product at higher temperatures. ${ }^{1,3}$ The latter allows rapid processing techniques, such as stamp forming or rubber pressing, with short cycle times and potentially low costs.

The production of fibre reinforced composites requires the impregnation of a fibrous reinforcement with a resin. A major disadvantage of using thermoplastic polymers is their high viscosity, in the range of 200-600 Pa s for the polyphenylene sulphide (PPS) at processing temperatures used in this study, which makes fabric impregnation more difficult. The impregnation can be eased by minimising the distance required for the matrix to flow. This can be achieved by mixing the two constituents before processing, ${ }^{4,5}$ for which several approaches have been developed: examples are film stacking, ${ }^{6,7}$ solvent impregnation ${ }^{8}$ or the use of commingled yarns. ${ }^{9-11}$

The present study focuses on the production of flat fabric reinforced thermoplastic laminates using a film stacking procedure. The Dutch based company Ten Cate Advanced Composites produces these specific laminates under the trade name Cetex. The laminates serve as a semifinished product and obtain their final

Faculty of Engineering Technology, University of Twente Drienerlolaan 5, PO Box 217, 7500AE Enschede, The Netherlands

*Corresponding author, email w.j.b.grouve@utwente.nl shape using for instance rubber pressing ${ }^{12}$ or autoclave processing. Figure 1 schematically shows the film stacking procedure. A stack, comprising alternate plies of reinforcing woven fabric and thermoplastic film, separated by steel or aluminium caul plates or PTFE foil, is placed between two press platens. The production process consists of three phases:

(i) heat the press to lower the matrix viscosity

(ii) increase the pressure to force the thermoplastic matrix material to impregnate the fabric

(iii) cool the press to solidify the laminates.

Currently, the processing parameters such as heating rate, processing temperature and processing pressure are determined using a trial and error procedure with extensive material inspection. The development of a predictive process model could provide an inexpensive and fast alternative to design the optimal processing cycle for new thermoplastic laminates, as well as to optimise the processing parameters for current Cetex laminates.

The development of such a process model is subject of the present paper. The first section presents a short experimental study to qualify the different stages in which consolidation takes place. The second section introduces a modelling approach treating the heating phase of the process and the impregnation phase separately. A transient thermal model predicts the through thickness laminate temperature as a function of time during the heating phase of the process, while a simple Darcy based model is used to account for the impregnation kinetics. An experimental programme to validate the thermal and impregnation model is presented in the third section. The consolidation quality is examined using both microscopy and by mechanical testing. The final conclusions are presented in the last section. 


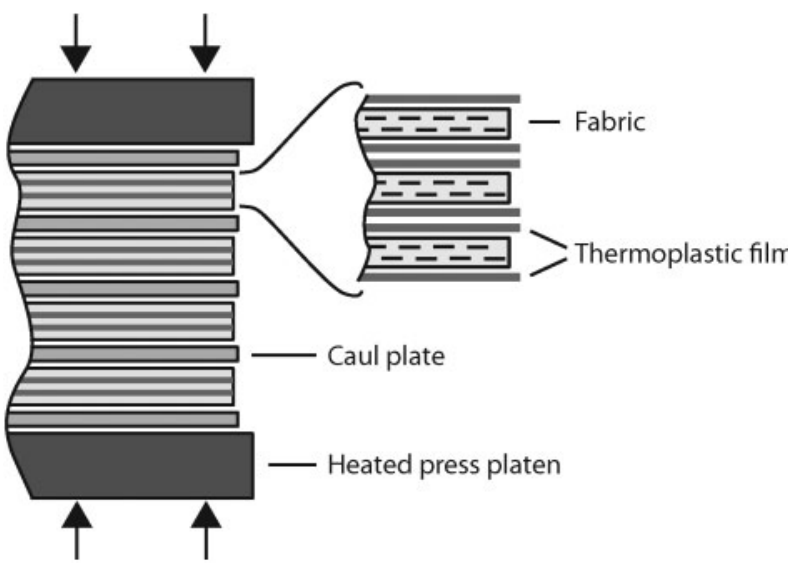

1 Schematic representation of film stacking production process

\section{Process description}

A fully consolidated laminate requires the thermoplastic resin to replace all the air in the fabric. This is achieved at elevated temperature by increasing the applied pressure and forcing the thermoplastic resin to impregnate the reinforcing fabric. The architecture of a woven fabric dictates that the impregnation takes place on two scales. The interbundle scale concerns the space between the bundles, while the intrabundle scale concerns the space between the individual filaments within the bundles. Based on the difference in characteristic pore dimensions of the two scales, it is assumed that impregnation on the interbundle scale will precede intrabundle impregnation.

A glass/PPS laminate was processed in an experimental press mounted in a tensile tester to validate this assumption. Ten Cate Advanced Composites provided eight-harness satin glass fabric and PPS film for this purpose. The tensile tester measures the applied pressure and the gap between the two press platens, while a thermocouple placed in the centre of the laminate records the temperature during the process. Figure 2 shows the applied pressure, the gap between the two press platens and the laminate temperature during the process. The press is heated to a processing temperature of $315^{\circ} \mathrm{C}$, while maintaining a pressure of $0 \cdot 1 \mathrm{MPa}$. The

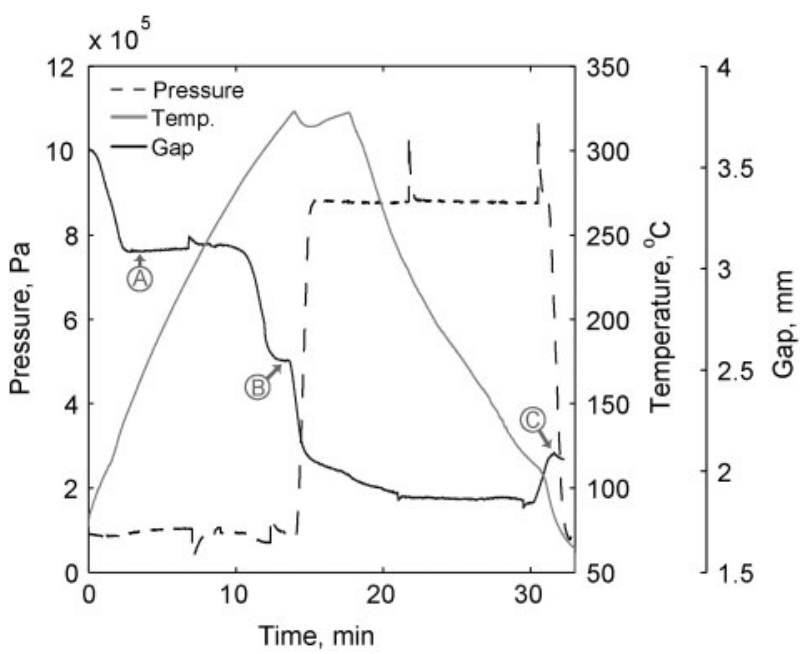

2 Processing variables measured during production of glass/PPS laminate

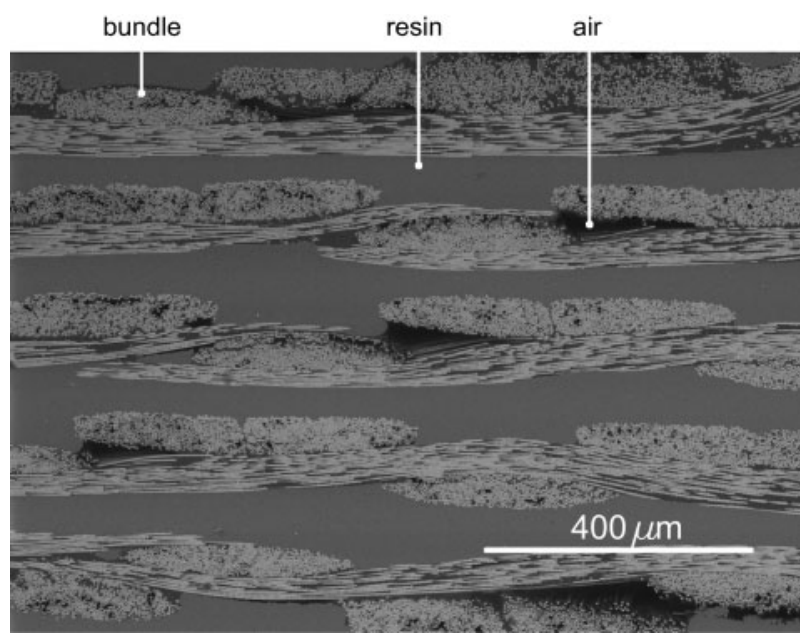

3 Cross-section of glass/PPS laminate at point A in Fig. 2

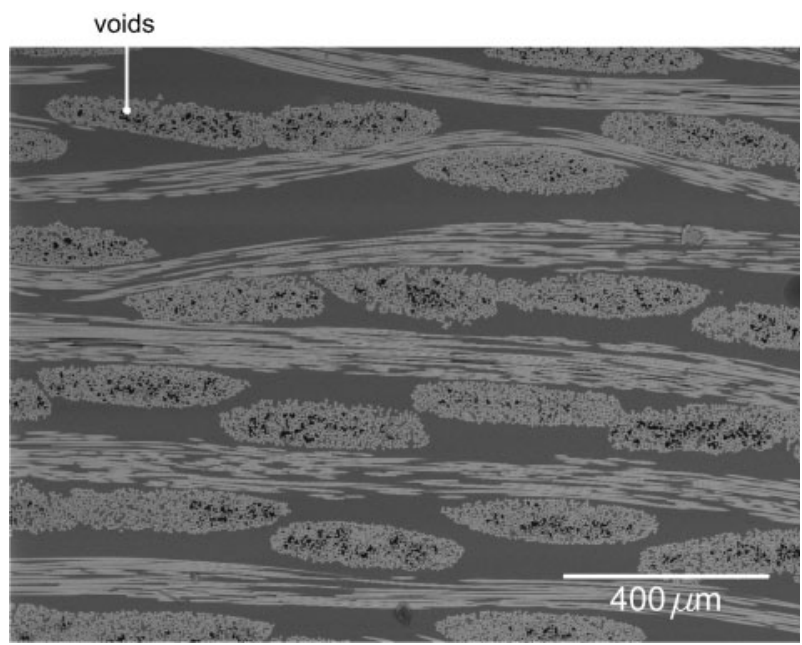

4 Cross-section of glass/PPS laminate at point B in Fig. 2

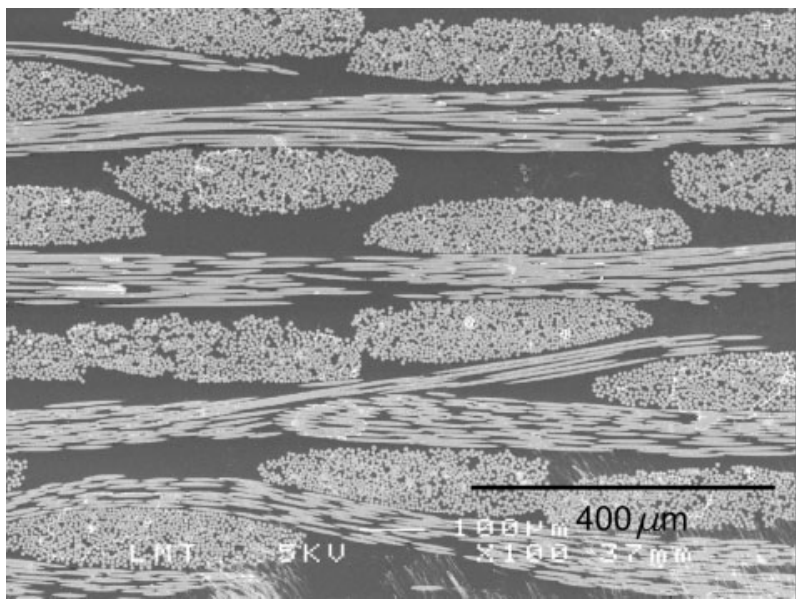

5 Cross-section of glass/PPS laminate at point $\mathrm{C}$ in Fig. 2

pressure is increased to $0.9 \mathrm{MPa}$, after which temperature and pressure are maintained for a consolidation time of $\sim 5 \mathrm{~min}$. Subsequently, the press is cooled down while maintaining the processing pressure. The measured displacement suggests that the consolidation proceeds in three stages (labelled A to C). Ijaz et al. ${ }^{13}$ 
observed a comparable evolution of the consolidation process for PET based commingled yarns.

Two additional laminates were processed to qualify the degree of impregnation at stage $\mathrm{A}$ and $\mathrm{B}$. The first stage starts when the glass transition temperature $\left(90^{\circ} \mathrm{C}\right)$ of the thermoplastic film is reached. The micrograph in Fig. 3 shows a cross-section of the glass/PPS laminate at stage A. It can be seen that the thermoplastic film plastically deforms and partly fills open interbundle scale pores of the fabric. The second impregnation stage starts at the melt temperature $\left(280^{\circ} \mathrm{C}\right)$ of the PPS thermoplastic film. The micrograph in Fig. 4 shows that impregnation at the interbundle scale is complete, i.e. the matrix material now surrounds the bundles. However, impregnation of the bundles themselves is not achieved yet. An increase in the applied pressure causes the last stage of impregnation: the applied pressure forces the thermoplastic matrix to impregnate the bundles. The micrograph in Fig. 5 corresponds to stage $\mathrm{C}$ and clearly shows that all the air inside the bundles is now replaced by matrix material.

The processing graph in Fig. 2 in combination with the micrographs in Figs. 3-5 shows that interbundle impregnation is achieved during the heating phase of the process, while intrabundle impregnation requires an increase in the applied pressure. Therefore, intrabundle impregnation is considered to be the rate determining stage of the process.

\section{Film stacking process model}

This section proposes a modelling approach to optimise the heating and bundle impregnation phase of the film stacking production process. First, a one-dimensional (1D) transient thermal model is proposed to predict the through thickness temperature distribution of the laminate during the heating phase of the process. The model provides the possibility to investigate the influence of stack composition and material properties on the time required to fully heat the stack. Second, a Darcy impregnation model is proposed to study the influence of applied pressure and processing temperature on the time required for bundle impregnation. The combination of both models allows optimisation of the film stacking process in terms of time and costs.

\section{Phase I: transient thermal model}

A simple transient 1D thermal model is used to predict the through thickness temperature distribution in the laminate as a function of time and applied platen temperature. The 1D heat conduction equation reads

$$
\frac{1}{\alpha[y, T(y, t)]} \frac{\partial T}{\partial t}=\frac{\partial^{2} T}{\partial y^{2}}
$$

in which $\alpha[\mathrm{y}, T(y, t)]$ represents the thermal diffusivity which is defined as the ratio of thermal conductivity $\lambda$ to volumetric heat capacity $\rho c_{\mathrm{p}}$

$$
\alpha=\frac{\lambda}{\rho c_{\mathrm{p}}}
$$

The thermal diffusivity varies over the thickness of the stack. The structure, and subsequently the thermal properties of the composite laminate change while heating the stack. The previous section showed that the film is partly forced into the open interbundle scale pores
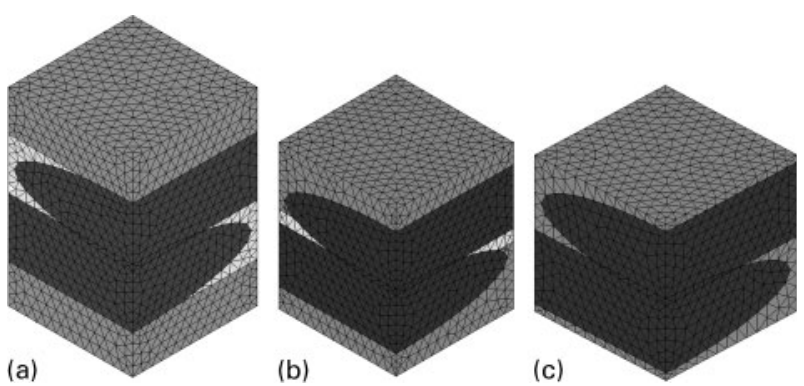

a $T<T_{\mathrm{g}} ; b T_{\mathrm{g}}<T<T_{\mathrm{m}} ; c T>T_{\mathrm{m}}$

6 Finite element units cells representing laminate during heating phase

at the glass transition temperature and that interbundle scale impregnation, is achieved above the melt temperature. The thermal diffusivity of the composite is therefore also a function of the local temperature.

A three-dimensional finite element analysis of representative unit cells was performed in Ansys to estimate the thermal conductivity of the glass/PPS composite laminate during the three different stages. The different unit cells during the process are shown in Fig. 6. The first unit cell consists of two ellipsoidal shaped bundles stacked between two thin thermoplastic films. The second unit cell shows that the film is partly forced into the interbundle scale pores of the fabric, while the third unit cell shows that interbundle scale impregnation is completed. The thermal conductivities of PPS ${ }^{14}$ and air equal $0 \cdot 29 \mathrm{~W} \mathrm{~m}^{-1} \mathrm{~K}^{-1}$ and $0.026 \mathrm{~W} \mathrm{~m}^{-1} \mathrm{~K}^{-1}$ respectively. Digital image analysis showed that the bundle has a fibre volume fraction of $0 \cdot 7$. The thermal conductivity of a bundle, in the direction transverse to the fibres, was estimated to be $0 \cdot 2 \mathrm{~W} \mathrm{~m}^{-1} \mathrm{~K}^{-1}$ using elementary finite element analysis. For the sake of simplicity, this value was also used for the thermal conductivity parallel to the fibre direction. Table 1 shows the resulting homogenised thermal properties for the different unit cells. The resulting steady state through the thickness thermal conductivity is seen to increase with the degree of consolidation.

Equation (1) is then solved for the stack comprising the homogenised laminates and tinplates or PTFE foil, subject to the following initial and boundary conditions

$$
\begin{aligned}
& T(y, 0)=T_{\text {start }} \\
& T(0, t)=T(h, t)=T_{\text {platen }}(t)
\end{aligned}
$$

in which $h$ corresponds to the thickness of the stack. Equation (1) is solved numerically by using an implicit finite difference approach on a fixed grid. The thermal diffusivities are compensated to account for the thickness

\begin{tabular}{|c|c|c|c|}
\hline Unit cell & Fig. $6 a$ & Fig. $6 b$ & Fig. $6 c$ \\
\hline Temp range, ${ }^{\circ} \mathrm{C}$ & $T<T_{\mathrm{g}}\left(90^{\circ} \mathrm{C}\right)$ & $T_{\mathrm{g}}<T<T_{\mathrm{m}}$ & $T_{\mathrm{m}}\left(280^{\circ} \mathrm{C}\right)<T$ \\
\hline 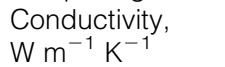 & $0 \cdot 15$ & $0 \cdot 23$ & 0.29 \\
\hline $\begin{array}{l}\text { Heat capacity, } \\
\mathrm{kJ} \mathrm{kg}^{-1} \mathrm{~K}^{-1}\end{array}$ & 0.82 & 0.82 & 0.82 \\
\hline Density, $\mathrm{kg} \mathrm{m}^{-3}$ & 1125 & 1405 & 1590 \\
\hline
\end{tabular}
change during the process.

Table 1 Thermal properties of different unit cells for glass/PPS 


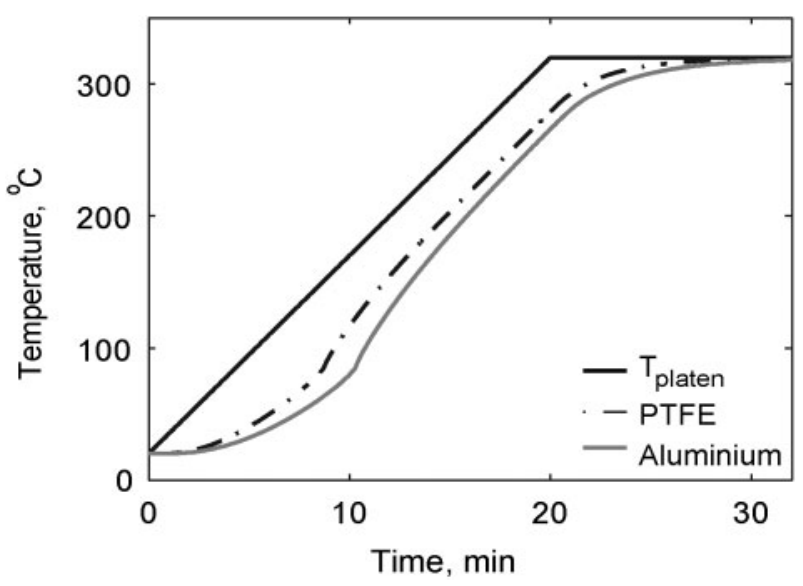

7 Temperature in centre of stack consisting of 10 [PPS/ glass/PPS $]_{4}$ laminates separated by either aluminium caul plates or PTFE foil

Figure 7 shows the temperature in the centre of a stack, consisting of 10 [PPS/glass/PPS $]_{4}$ laminates, separated by either aluminium caul plates or PTFE foil, during heating. The aluminium caul plate has a thickness of $1 \cdot 1 \mathrm{~mm}$, while the PTFE foil has a thickness of $0.25 \mathrm{~mm}$. The thermal properties of these materials are listed in Table 2. The figure shows that the application of PTFE foil between the laminates promotes the through thickness heat conduction in the stack; the temperature difference diminishes faster compared to the aluminium caul plates.

\section{Phase II: Darcy intrabundle impregnation model}

The micrographs in the previous section show that impregnation on the interbundle scale is achieved while heating to the processing temperature. Impregnation of the bundles themselves, however, requires an increase in the applied pressure. It is, therefore, assumed that the bundle impregnation governs the total impregnation time. Bundle impregnation with a thermoplastic resin has been subject of research in a number of comparable studies: for instance in commingled yarn composites ${ }^{9,11}$ and film stacking of knitted fabrics. ${ }^{15}$ In general, it is assumed that all fibre bundles undergo impregnation simultaneously and all the bundles have an identical geometry. This assumption allows the fabric to be divided into repetitive elements or unit cells, of e.g. a rectangular, ${ }^{8}$ a circular ${ }^{10}$ or an ellipsoidal ${ }^{16}$ shape. Furthermore, it is assumed that flow takes place in a direction orthogonal to the fibres only and that the pressure inside the bundles equals the atmospheric pressure. A similar approach is adopted in this work to model the impregnation of the film stacked glass/PPS laminates.

\section{Unit cell}

The unit cell used in this work, shown in Fig. 8a, consists of two bundles in a thermoplastic resin. The unit cell length $L$ and width $W$ are defined as the

Table 2 Thermal properties of separator materials

\begin{tabular}{|c|c|c|c|}
\hline & 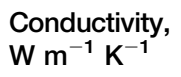 & $\begin{array}{l}\text { Heat capacity, } \\
\mathrm{kJ} \mathrm{kg}^{-1} \mathrm{~K}^{-1}\end{array}$ & $\begin{array}{l}\text { Density, } \\
\mathrm{kg} \mathrm{m}^{-3}\end{array}$ \\
\hline Aluminium caul plate & 237 & 0.90 & 2700 \\
\hline PTFE foil & 0.29 & 0.82 & 1590 \\
\hline
\end{tabular}

reciprocal of the warp count and weft count, which are listed in Table 3. The total volume of the unit cell $V_{\text {tot }}$ equals the sum of the fibre $V_{\mathrm{f}}$, the matrix $V_{\mathrm{m}}$ and the void $V_{\mathrm{v}}$ volumes

$$
V_{\text {tot }}(t)=L \cdot W \cdot h(t)=V_{f}(t)+V_{m}(t)+V_{v}(t)
$$

It is assumed that the fibre volume and matrix volume in the unit cell are constant, while the air is allowed to evacuate the unit cell via channels formed by the unimpregnated part of the bundles. Continuity of matrix material yields

$$
V_{\mathrm{m}}(t)=V_{\mathrm{m}}^{\mathrm{I}}(t)+V_{\mathrm{m}}^{\mathrm{B}}(t)=\text { const. }
$$

in which the superscripts $I$ and $B$ refer to the interbundle and intrabundle space respectively. The analysis in the previous section showed that impregnation at the interbundle scale is completed during the heating phase of the process. The air, initially present between the bundles, is assumed to have evacuated via the dry bundles. It is therefore assumed that when the intrabundle impregnation starts

$$
V_{\mathrm{v}}^{\mathrm{I}}(t=0)=0
$$

During the bundle impregnation, matrix material flows from the interbundle space into the bundles, thereby decreasing the total intrabundle void volume $V_{\mathrm{v}}^{\mathrm{B}}$. The fibre bundles have an elliptical cross-section, as shown schematically in Fig. $8 b$. Digital image analysis on laminates consolidated with varying pressures, ranging from 0.4 to $1.0 \mathrm{MPa}$, showed that both bundle shape and bundle fibre volume $v_{\mathrm{f}, \mathrm{b}}$ fraction are remarkably constant, irrespective of the applied pressure. It is therefore assumed that the bundles are rigid entities, which also implies that bending of the bundles is responsible for the fabric compaction stress within the range of processing conditions applied here. The total intrabundle void volume in the unit cell is now defined as

$$
V_{\mathrm{v}}^{\mathrm{B}}(t)=\left(1-v_{\mathrm{f}, \mathrm{b}}\right)(L+W) \cdot \pi a(t) b(t)
$$

in which $a(t)$ and $b(t)$ are defined as the major and minor radii of the flow front position.

\section{Impregnation kinetics}

An analysis by van West et al. ${ }^{17}$ showed that an equivalent $1 \mathrm{D}$ radial analysis can be used to model the impregnation kinetics for ellipsoidal bundle shapes. The equivalent radius $r$, as shown in Fig. $8 c$, yields

$$
r=2^{1 / 2} \frac{a b}{\left(a^{2}+b^{2}\right)^{1 / 2}}
$$

The major and minor radii of the bundles in the Cetex glass S303 fabric were obtained by digital image analysis and are listed in Table 3 . The equivalent initial bundle radius $r_{0}=r(t=0)$, as determined using equation (8), equals $75 \mu \mathrm{m}$ for this specific fabric. Combining Darcy's law and the continuity equation for the liquid phase in cylindrical coordinates, under the assumption of rigid bundles, gives an expression ${ }^{10}$ for the impregnation rate $\mathrm{d} r / \mathrm{d} t$ as a function of the resin pressure $p_{\mathrm{r}}$ and flow front position $r$ 

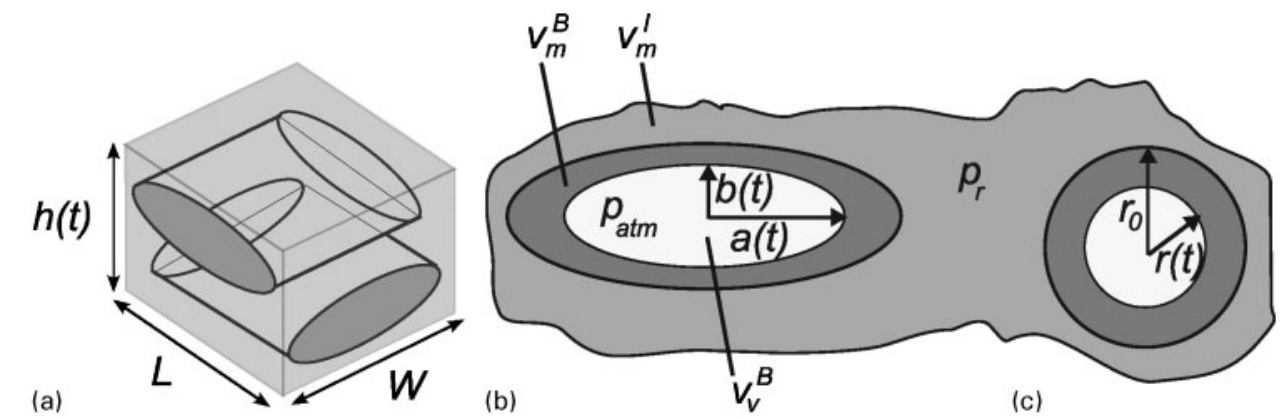

$a$ unit cell dimensions, $\boldsymbol{b}$ intrabundle impregnation and $\boldsymbol{c}$ circular bundle representation

$$
r \ln \left(\frac{r}{r_{0}}\right) \frac{\mathrm{dr}}{\mathrm{d} t}=-\frac{K}{\left(1-v_{\mathrm{f}}\right) \mu} p_{\mathrm{r}}
$$

in which $p_{\mathrm{r}}$ is the resin pressure at $r=r_{0}, K$ is the bundle permeability and $\mu$ the resin viscosity.

The applied pressure $p_{\mathrm{a}}$ is distributed over the resin pressure $p_{\mathrm{r}}$ and fabric compaction stress $\sigma_{\mathrm{f}}$. Two limiting cases can be identified for the resin pressure. At the upper bound all of the applied pressure is carried by the resin pressure, while at the lower bound the applied pressure is carried by the resin and compaction stress in a parallel connection without taking the fibre volume fraction $v_{\mathrm{f}}$ into account. The resin pressure therefore satisfies the following relation

$$
p_{\mathrm{a}} \geq p_{\mathrm{r}} \geq p_{\mathrm{a}}-\sigma_{\mathrm{f}}
$$

The lower bound is the most conservative in terms of bundle impregnation time and is therefore used in this analysis

$$
p_{\mathrm{r}}=p_{\mathrm{a}}-\sigma_{\mathrm{f}}\left(\varepsilon_{\mathrm{z}}\right)
$$

The stress-strain compaction curve of the fabric, used here, is acquired experimentally by compacting eight plies of dry fabric between two flat surfaces. The experimental data are fitted with a power law function

$$
\sigma_{\mathrm{f}}\left(\varepsilon_{\mathrm{z}}\right)=c_{0} \cdot \varepsilon_{\mathrm{z}}^{\mathrm{c}_{1}}
$$

in which $c_{0}$ and $c_{1}$ are constants, listed in Table 3 , and $\varepsilon_{\mathrm{z}}$ is the fabric compaction strain

$$
\varepsilon_{\mathrm{z}}(h)=\frac{h-h_{0}}{h_{0}}
$$

with $h$ the current fabric thickness and $h_{0}$ the initial thickness, as given in Table 3 .

The bundle permeability $K$ is assumed constant based on the observation that both bundle geometry and bundle fibre volume fraction are independent of the applied pressure. The fibre volume fraction $v_{\mathrm{f}}$ and packing type of a bundle were approximated from

Table 3 Dimensional and mechanical properties of glass 8-H satin S303 fabric

\begin{tabular}{ll}
\hline Cetex $\mathbf{S 3 0 3}$ & Value \\
\hline Bundle major $a_{0}, \mu \mathrm{m}$ & 210 \\
Bundle minor $b_{0}, \mu \mathrm{m}$ & 55 \\
Warp count, $\mathrm{m}^{-1}$ & 2200 \\
Weft count, $\mathrm{m}^{-1}$ & 2280 \\
Thickness $h_{0}, \mathrm{~mm}$ & $0 \cdot 3$ \\
Powerlaw constant $c_{0}, \mathrm{~Pa}$ & $1 \cdot 15 \times 10^{7}$ \\
Powerlaw exponent $c_{1}$ & $2 \cdot 68$ \\
\hline
\end{tabular}

micrographs of fully consolidated laminates. Digital image analysis showed that a bundle fibre volume fraction of 0.7 with a hexagonal packing was most appropriate. The bundle permeability is then calculated according to the formulation developed by Gebart $^{18}$ and found to equal $K=9 \times 10^{-14} \mathrm{~m}^{2}$. Furthermore, it is assumed that the flow is Newtonian, since the shear rates are low, and that impregnation takes place at isothermal conditions. The viscosity $\mu$ of the PPS film as a function of temperature, in Kelvin, is obtained from data provided by the supplier, ${ }^{19}$ and fitted on the WLF model

$$
\mu(T)=D_{1} \exp \left[\frac{-A_{1}\left(T-T^{*}\right)}{A_{2}+T-T^{*}}\right]
$$

The constants $D_{1}, A_{1}, A_{2}$ and $T^{*}$ for the PPS film used here are listed in Table 4.

\section{Implementation and results}

Combining equations (4) and (7) yields a relation between the unit cell height $h(t)$ and the intrabundle void volume $V_{\mathrm{v}}^{\mathrm{B}}$

$$
L \cdot W \cdot h(t)=V_{\mathrm{f}}+V_{\mathrm{m}}+\left(1-v_{\mathrm{f}, \mathrm{b}}\right)(L+W) \cdot \pi a(t) b(t)
$$

which is subject to

$[a(t), b(t)]=f\left[p_{\mathrm{r}}(t), t\right]$, equations (8) and (9)

$p_{\mathrm{r}}=p_{\mathrm{a}}-\sigma_{\mathrm{f}}\left(\varepsilon_{\mathrm{z}}\right)$, equation (11)

This system of equations is solved by simple Picard iterations and implemented in an MS Excel worksheet for industrial use. The MS Excel application was subsequently used to determine the intrabundle impregnation time for the glass/PPS system as a function of applied pressure and temperature. The results were shown to converge with decreasing time step size. Figure 9 shows the bundle impregnation time as a function of processing pressure and temperature for glass/PPS thermoplastic laminates. The figure shows that the bundle impregnation for the glass/PPS laminates is achieved in less than $25 \mathrm{~s}$. The predicted impregnation time is significantly shorter than the typical consolidation time for these laminates, which is

Table 4 Characteristics of PPS film

\begin{tabular}{ll}
\hline PPS film & Value \\
\hline Viscosity constant $D_{1}$, Pa s & $1.07 \times 10^{13}$ \\
Viscosity constant $A_{1}$, & 29.8 \\
Viscosity constant $A_{2}, \mathrm{~K}$ & 51.6 \\
Viscositty constant $T^{*}, \mathrm{~K}$ & 373 \\
Thickness, $\mu \mathrm{m}$ & 60
\end{tabular}




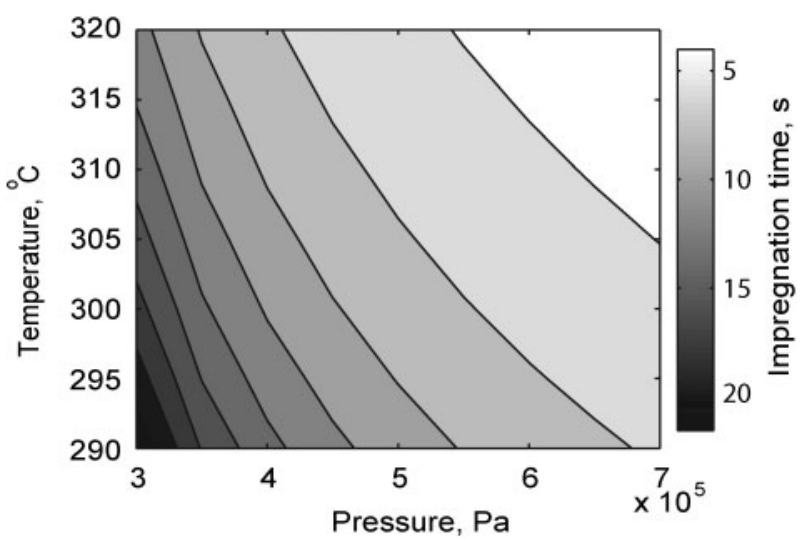

9 Bundle impregnation times for glass/PPS laminates as function of applied pressure and temperature

in the order of $15 \mathrm{~min}$. An experimental programme was designed to study the validity of the predicted intrabundle impregnation time.

\section{Experimental work}

An experimental programme was designed to validate the transient thermal model and bundle impregnation model. The present section compares obtained experimental data with the model predictions and discusses the obtained results. The Dutch based company Ten Cate AC kindly provided $8 \mathrm{H}$ glass $\mathrm{S} 303$ woven fabric and PPS thermoplastic film. The fabric has an areal density of $300 \mathrm{~g} \mathrm{~m}^{-2}$ and an initial thickness of approximately $0.3 \mathrm{~mm}$, while the PPS film has a thickness of $60 \mu \mathrm{m}$. The thermoplastic PPS has a glass transition temperature of $90^{\circ} \mathrm{C}$ and a melt temperature of $280^{\circ} \mathrm{C}$. The fabric and film were stacked in a [PPS/glass/PPS $]_{n}$ layup. A fully consolidated laminate has an overall fibre volume fraction of approximately $0 \cdot 5$.

\section{Validation of thermal model}

A glass/PPS laminate with a $\left[\mathrm{PPS} / \text { glass }\left(0^{\circ}\right) / \mathrm{PPS}\right]_{15 \mathrm{~s}}$ layup was produced in an experimental press. Sixteen thermocouples, placed in the bottom half of the laminate between every two PPS films, measured the through thickness temperature distribution during heating, as presented in Fig. 10. The symmetry plane of the laminate corresponds with the top of the figure. A large temperature difference of $\sim 50^{\circ} \mathrm{C}$ was found over the laminate thickness during the heating process. The transient thermal model with variable diffusivities was validated by fitting the measured temperature at the bottom of the laminate with a polynomial function and using this as a boundary condition in the thermal model. The predicted and measured temperatures in the centre as well as the measured and fitted edge temperature are shown in Fig. 11. Despite the simplicity of the implemented model the predicted temperature corresponds well with the experimental results for the glass/PPS system used in this research. The applicability of the proposed model for other thermoplastic laminates is subject of future research.

\section{Validation of Darcy impregnation model}

The Darcy bundle impregnation model predicted an impregnation time of less than $25 \mathrm{~s}$ for a processing temperature above $290^{\circ} \mathrm{C}$ and a pressure above $0 \cdot 3 \mathrm{MPa}$, while the typical consolidation time used in

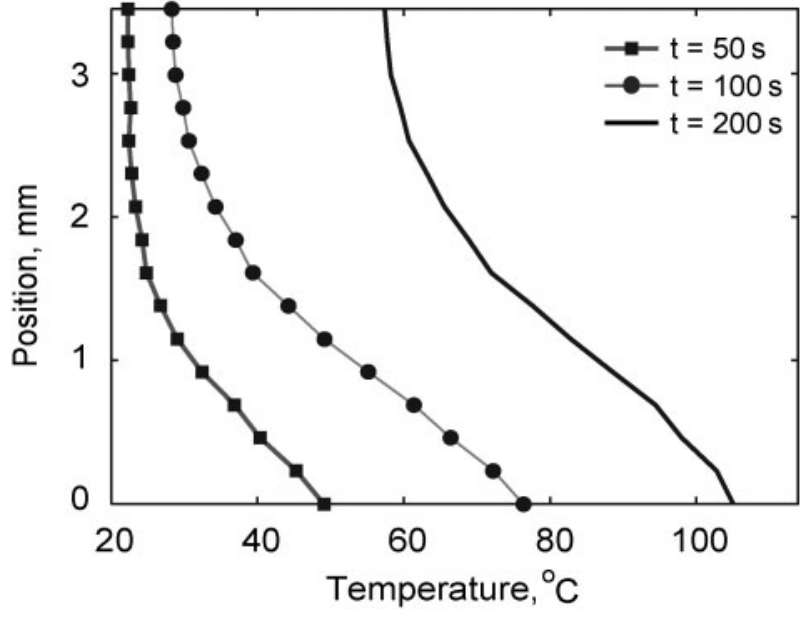

10 Measured temperature distribution over bottom half of $[P P S / g l a s s / P P S]_{15 s}$ laminate after 50,100 and $200 \mathrm{~s}$

practice is in the order of $15 \mathrm{~min}$. Because of this large discrepancy, it was decided to design a comprehensive experimental programme. The values of the processing pressure, temperature and consolidation time were all varied to study their influence.

A total of 27 laminates with a $\left[\mathrm{PPS} / \text { glass }\left(0^{\circ}\right) / \mathrm{PPS}\right]_{4 \mathrm{~s}}$ were produced. The laminates were produced in a Fontijne laminate press, with $0.5 \times 0.5 \mathrm{~m}$ platens. The press was heated to the processing temperature after which the stack was placed between the platens. Subsequently, the press was closed with a holding pressure of $0 \cdot 1 \mathrm{MPa}$ until the laminate was fully heated, which takes approximately $30 \mathrm{~s}$. The temperature was recorded with a thermocouple placed in the centre of the stack. The pressure is increased to the desired processing value after which pressure and temperature were maintained for the defined consolidation time. The pressure was maintained until the laminate reached room temperature, while cooling down after consolidation. The time above the melt temperature during cooling was measured to be at most $4 \mathrm{~min}$. The cooling rate was kept constant at $10^{\circ} \mathrm{C} \mathrm{min}{ }^{-1}$ for all the laminates; the processing pressure, temperature and consolidation time, however, were varied. Three levels were chosen for each processing parameter, as listed in Table 5. The given consolidation time of $0 \mathrm{~min}$ corre-

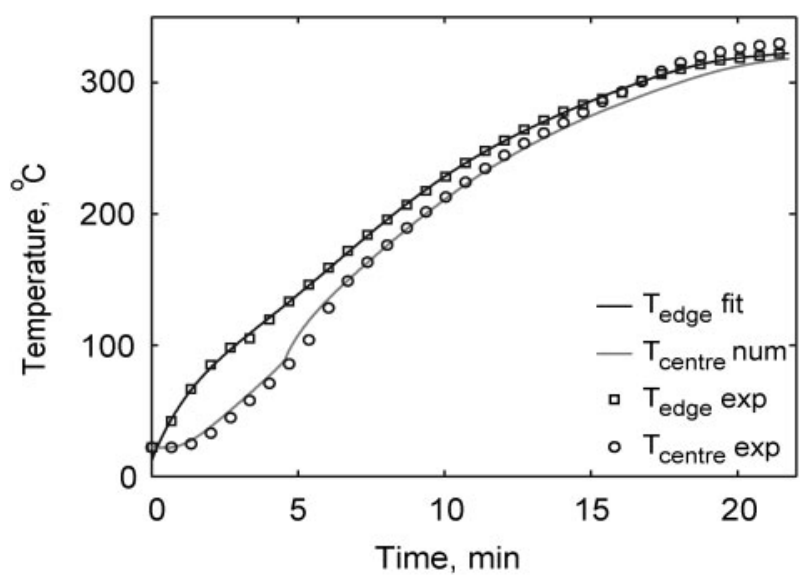

11 Comparison between predicted and measured temperature in centre of $[\mathrm{PPS} / \mathrm{glass} / \mathrm{PPS}]_{15 \mathrm{~s}}$ laminate 
Table 5 Different levels for processing parameters for 27 test laminates

\begin{tabular}{lccc}
\hline Pressure, $\mathrm{MPa}$ & 0.4 & 0.7 & $1 \cdot 0$ \\
Temperature, ${ }^{\circ} \mathrm{C}$ & 300 & 315 & 330 \\
Consolidation time, min & 0 & $2 \cdot 5$ & 5 \\
\hline
\end{tabular}

sponds to the case where the press was cooled immediately after the pressure was applied.

After processing, specimens were cut from the laminates and visually inspected using a scanning electron microscope. Intrabundle impregnation was achieved for all the laminates. Figures 12 and 13 show the micrographs obtained from the laminate produced using the most conservative processing parameters, that is a pressure of $0.4 \mathrm{MPa}$, a temperature of $300^{\circ} \mathrm{C}$ and a consolidation time of $0 \mathrm{~min}$. The micrographs show that intrabundle impregnation has been achieved. However, the micrograph in Fig. 13 also shows some microvoids between the individual filaments. The size and quantity of these microvoids was seen to decrease with increasing processing pressure, whereas processing temperature and consolidation time showed no influence.

The in-plane shear strength of the laminates was determined by performing a $\pm 45^{\circ}$ tensile test. The tests were performed according to the ASTM D3518 standard. A total of three samples were cut from each of the laminates. The averaged standard deviation for each laminate on the measured shear strength was $1 \cdot 4 \%$, while the maximum standard deviation was found to be $5 \cdot 3 \%$. Figure 14 shows the averaged shear strength of the specimens as a function of consolidation time. The marker shape denotes the applied processing pressure, while the marker colour denotes the applied processing temperature. The figure shows that there is no apparent relation between shear strength and consolidation time. The processing temperature, however, seems to have a more pronounced effect. Figure 14 shows that the laminate strength seems to decrease as the processing temperature increases, which may be attributed to degradation of the polymer matrix. Interlaminar shear strength tests, according to the ASTM D2344 standard, performed on five specimens from each laminate showed similar results.

For comparison, a laminate was processed at a pressure of $1.0 \mathrm{MPa}$, a temperature of $315^{\circ} \mathrm{C}$ and with a consolidation time, as used in practice, of $15 \mathrm{~min}$. The

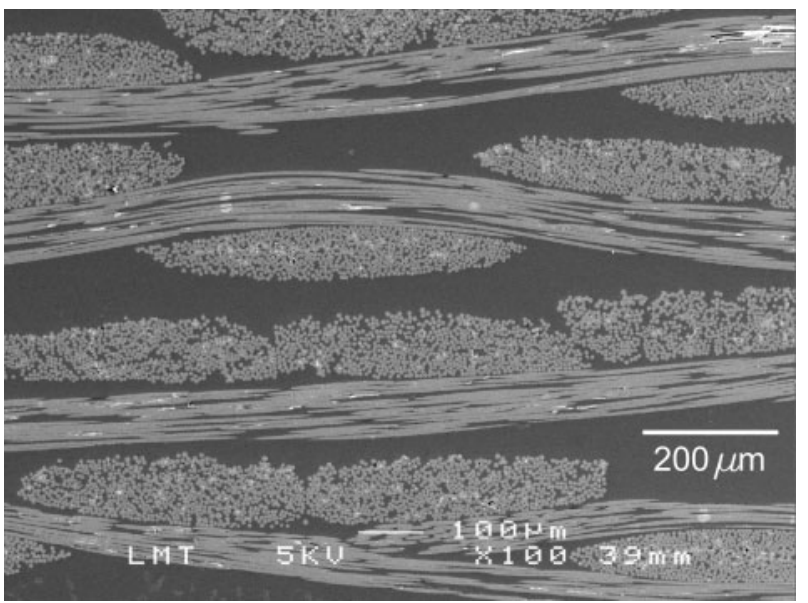

12 Micrograph of cross-section of glass/PPS laminate (pressure: $0.4 \mathrm{MPa}$, temperature: $300^{\circ} \mathrm{C}$, consolidation time: $0 \mathrm{~min}$ )

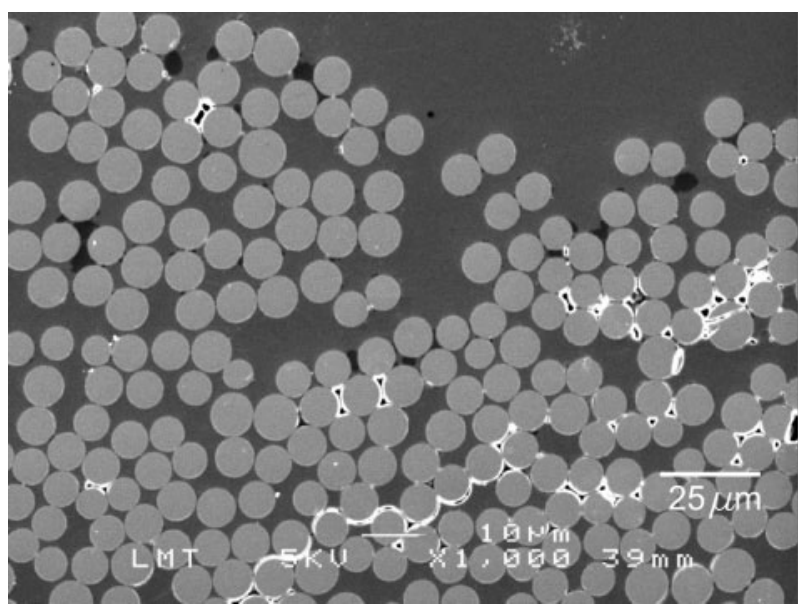

13 Micrograph of cross-section of glass/PPS laminate (pressure: $0.4 \mathrm{MPa}$, temperature: $300^{\circ} \mathrm{C}$, consolidation time: 0 min)

averaged shear strength, measured on three samples of this laminate, was found to be $69 \mathrm{MPa}$, with a standard deviation of $1 \cdot 1 \%$. The measured shear strength corresponds well with the result shown in figure: the increase in consolidation time has no influence on the measured shear strength.

Based on the obtained experimental results it can be concluded that the consolidation time of the glass/PPS laminates can be reduced significantly, as the impregnation model suggested. Intrabundle impregnation was found to be completed for all laminates and furthermore, the measured shear strength and interlaminar shear strength was found to be independent of consolidation time. The influence of the small microvoids, present between the filaments at low processing pressures, on mechanical properties needs to be further investigated. The voids might act as crack initiators and thereby cause premature failure.

\section{Conclusions}

The consolidation process of film stacked glass/PPS laminates was investigated. A 1D transient thermal model was proposed to optimise the heating phase of the process. The structural change of the material is taken into account by implementing a temperature dependent thermal diffusivity. Despite the simplicity of the model, good agreement with experimental data was observed.

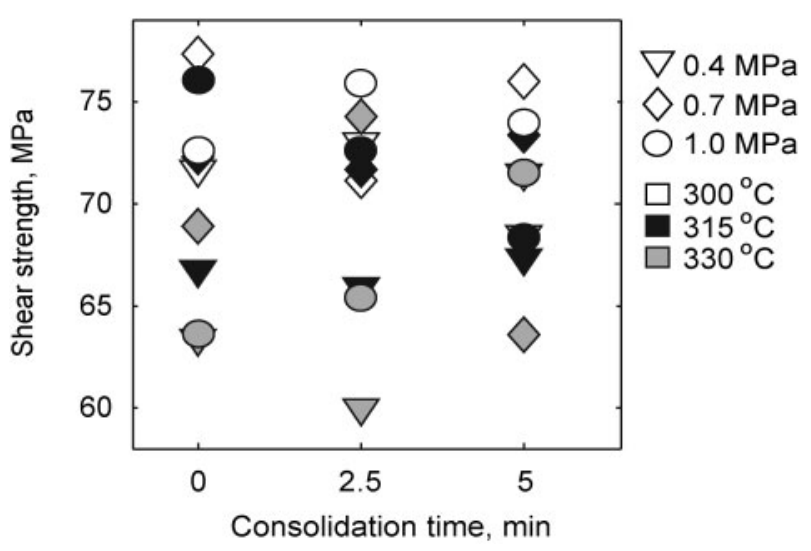

14 Shear strength as function of consolidation time for different processing pressures and temperatures 
The authors aim to apply the thermal model on alternative thermoplastic laminates in the near future.

The impregnation of the fabric takes place on different scales. It was observed that intrabundle impregnation is the rate determining step. A simple Darcy based impregnation model is applied to calculate the impregnation time of the fabric. The obtained results predict an impregnation time in the order of seconds, while the typical consolidation time used in practice is in the order of $15 \mathrm{~min}$. An extensive experimental programme showed that the consolidation time can be reduced significantly.

\section{Acknowledgements}

This work was performed with the support of from the Netherlands Agency for Aerospace Programmes (NIVR) under contract number SRP-59621UT, Ten Cate AC and Reden Research and Development. This support is gratefully acknowledged by the authors.

\section{References}

1. U. K. Vaidya and K. K. Chawla: Int. Mater. Rev., 2008, 53, (4), $185-218$.

2. J. M. Henshaw, W. Han and A. D. Owens: J. Thermoplast. Compos. Mater., 1996, 9, (1), 4-20.

3. J. Diaz and L. Rubio: J. Mater. Process. Technol., 2003, 143-144, (1), 342-346
4. C. Mayer: 'Prozeßanalyse und Modellbildung bei der Hestellung gewebeverstärkter thermoplastischer HalbZeuge', $\mathrm{PhD}$ thesis, Universität Kaiserslautern, DE, 1999.

5. A. G. Gibson and J.-A. Månson: Compos. Manuf., 1992, 3, (4), 223-233.

6. X. Wang, C. Mayer and M. Neitzel: Polym. Compos., 1997, 18, (6), 701-710.

7. S. T. Jespersen, M. D. Wakeman, V. Michaud, D. Cramer and J.-A. E. Månson: Compos. Sci. Technol., 2008, 68, (7-8), 18221830.

8. R. Phillips, D. A. Akyüz and J.-A. E. Månson: Composites A, 1998, 29A, (4), 395-402.

9. L. Ye, K. Friedrich, J. Kästeland and J.-W. Mai: Compos. Sci. Technol., 1995, 54, (4), 349-358.

10. N. Bernet, V. Michaud, P.-E. Bourban and J.-A. E. Månson: J. Compos. Mater., 1999, 33, (8), 751-772.

11. V. Klinkmüller, M.-K. Ulm, M. Steffens, K. Friedrich and B.-S. Kim: Appl. Compos. Mater., 1995, 1, (5), 351-371.

12. E. Lamers, R. Akkerman and S. Wijskamp: Int. J. Form. Process., 2003, 6, (3-4), 443-463.

13. M. Ijaz, M. Robinson, P. N. H. Wright and A. G. Gibson: J. Compos. Mater., 2007, 41, (2), 243-261.

14. J. Masamoto: in 'Polymer data handbook', (ed. J. E. Mark), 714 721; 1999, Oxford, Oxford University Press.

15. O. Rozant, V. Michaud, P.-E. Bourban and J.-A. E. Månson: Polym. Compos., 2001, 22, (3), 432-443.

16. L. Ye and K. Friedrich: J. Mater. Process. Technol., 1995, 48, 317324.

17. B. P. van West, R. B. Pipes, M. Keefe and S. G. Advani: Compos. Manuf., 1991, 12, 417-427.

18. B. Gebart: J. Compos. Mater., 1992, 26, (8), 1100-1133.

19. Ticona Engineering Polymers, available at: http://www.ticona.com/ home 